\title{
CARTOGRAFANDO CASOS DE VIOLÊNCIA DE GÊNERO EM UM GRUPO NO FACEBOOK
}

Adriane Gomes Araújo Costa. Alessandra Alexandre Freixo $\left.{ }^{*}\right)$

\section{VOCÊ ESTÁ NA CARTOGRAFIA}

Bem-vinda/vindo a esta cartografia que traçou e traça caminhos no universo feminino adolescente sobre violências de gênero, utilizando a rede social Facebook Messenger. O eixo norteador que nos levou a desenvolver esta pesquisa, cartografando as subjetividades das adolescentes convidadas, é conhecer as formas como são construídas as relações de violência de gênero entre adolescentes de uma escola municipal em Coração de Maria, Bahia, Brasil.

Mas por que conhecer as formas como são construídas as relações de violência de gênero? É sabido, principalmente pelas adolescentes/mulheres, que existem inúmeras situações do cotidiano feminino escolar que são repletas de julgamento e condenação baseados nessas relações, mas a intenção aqui não foi falar para as participantes da pesquisa o que existe em suas vidas (se existir), mas permear caminhos que possibilitem reflexão que as permita reconhecer e identificar, em situações cotidianas, os impactos das relações de gênero e sexualidade que acabam resultando em diversas formas de violência de gênero, na tentativa de conhecê-las como adolescentes que carregam consigo as "marcas" subjetivadas de uma comunidade altamente patriarcal.

Para ficar ainda mais próximo do cotidiano dessas adolescentes, a rede social Facebook, que é uma mídia social utilizada em larga escala, nos forneceu uma sala de encontro virtual, que nos permitiu conversar com mais liberdade e menos timidez. Por isso, optamos por organizar este trabalho baseando-nos nesta rede social, pois utilizamos termos próprios dela para nomear e destacar os aspectos mais importantes de nossa cartografia.

As interações sociais no ciberespaço podem ser de forma síncrona ou assíncrona (RECUERO, 2011). Desse modo, existem diversas maneiras de interagir no espaço virtual. Conversas em tempo real e chats são exemplos de uma interação social síncrona, que ocorre

\footnotetext{
${ }^{(*)}$ Adriane G. Costa. Licenciada em Ciências Biológicas pela Universidade Estadual de Feira de Santana (UEFS). Orcid: <https://orcid.org/0000-0003-3171-3831>.
}

Alessandra A. Freixo. Professora Titular do Departamento de Educação da Universidade Estadual de Feira de Santana. Ordic: <HTTPS://orcid.org/0000-0003-3566-8302>. 
principalmente através do Whatsapp e Facebook Messenger; na assíncrona, as pessoas podem deixar recados no Whatsapp e no Messenger, postar na linha do tempo do Facebook, colocar legendas tendenciosas nas fotos do Instagran e Facebook. Enfim, existem várias opções de interação na vida social na Internet.

Outro aspecto importante, principalmente na fase escolar de um/uma adolescente,é a vaidade, como parte do ritual de passagem para a adolescência (BRETAS et al., 2008). A vaidade é aflorada e é reforçada através do uso das redes sociais, do incessante desejo de mostrar-se belos e belas nas fotos para receber mais curtidas e mais comentários. Desta forma os adolescentes parecem projetar sua imagem pelas redes sociais, que são reforçadas pelos feedbacks (curtir e comentários) de seus amigos (CORRÊA; KODATO, 2014 p. 91). À medida que as curtidas e comentários aumentam em suas publicações, sua visibilidade aumenta, atraindo mais solicitações de amizade, se tornando uma adolescente ou um adolescente popular.

No Facebook, a atração é sentida e construída por meio de imagens de um corpo que muitas vezes é uma abstração, um conjunto numérico, digitalizado apenas para ser consumido virtualmente, pois foi "desenhado exclusivamente para ser exibido e observado" (SIBILIA, 2006, p. 284). Às vezes há até uma construção de um personagem em cima de si mesmo, escrevendo legendas que despertam para algo ou alguém. $\mathrm{O}$ eu privado torna-se uma representação pública na Internet que se exibe para uma plateia abstrata e anônima (ILLOUZ, 2011, p. 112). Dessa forma, passam a conhecer um ao outro, da maneira que deseja ser conhecido.

O Facebook, assim como as demais mídias sociais, oferece um ambiente para exposição autônoma do "eu privado". A sinceridade e a duplicidade podem ser vividas com intensidade nas redes sociais, pois a tela do smartphone/Desktop/Tablet confere a sensação de segurança contra críticas de toda natureza, longe do constrangimento face a face. Desse modo, as conversas nas redes sociais podem ser produtivas, visto que o conforto que a mesma proporciona a suas e seus usuárixs, permite a discussão de assuntos fundamentais, mas que ainda são polêmicos. Um exemplo, falar sobre sexualidade ainda é embaraçoso para muitas pessoas, o Facebook pode auxiliar nesse processo. Ao pronunciar a palavra sexualidade em determinados ambientes, inclusive na escola, a primeira coisa sugerida é o sexo enquanto relação entre corpos de homens e mulheres.

A sexualidade - o sexo, como se dizia — parecia não ter nenhuma dimensão social; era um assunto pessoal e particular que, eventualmente, se confidenciava a uma amiga próxima. Viver plenamente a sexualidade era, em princípio, uma prerrogativa da vida adulta, a ser partilhada com um parceiro do sexo oposto (LOURO, 2000a, p. 4). 
Entretanto, há que se considerar que a sexualidade supõe ou implica mais do que corpos adultos, que nela estão envolvidos fantasias, valores, linguagens, rituais, comportamentos mobilizados ou postos em ação para expressar desejos e prazeres. Enfim, compreender a sexualidade como um constructo histórico, como sendo produzida na cultura, cambiante, carregada da possibilidade de instabilidade, multiplicidade e provisoriedade (LOURO, 2007).

As relações de gênero são constuctos históricos de relações de poder que estruturam toda a sociedade. A mulher, enquanto sujeito, foi suprimida por uma construção social patriarcal, na qual não possuía o livre direito de expressar sua sexualidade. Desde a infância é violentada de diversas formas.

Acerca da terminologia violência pode-se dizer que é um termo de múltiplos significados que vem sendo utilizado para nomear desde as formas mais cruéis de tortura até as formas mais "sutis" da violência que tem espaço na família, nas empresas, entre outras. Logo, cabe mencionar que alguns estudiosos esboçam definições abrangentes da violência, onde as condições sociais, a distribuição desigual de bens e informações são geradores de violência tanto quanto os episódios agudos (a violência física) (SANTANA, 2010 p. 90).

Há um disciplinamento do corpo e do intelecto para enquadrar-se nos padrões da menina e da mulher ideal: meiga, compassiva, mãe e esposa em tempo integral, pois o sucesso e o infortúnio do seu casamento seriam sua responsabilidade. Enquanto isso, é incutido no homem desde o nascimento uma personalidade 'heróica', não deve demonstrar suas emoções. O homem deve ser o chefe da família, garantindo o subsídio financeiro e a submissão de sua esposa e filhos.

Daí se observa que a sociedade patriarcal traçou um perfil do que é ser homem e mulher, visto que algumas características cessam o que é próprio de cada um deles, pois é o gênero que determina não apenas quem faz o quê, mas também quem toma as decisões, haja vista que ambos desempenham um papel produtivo e comunitário nas esferas familiar, cultural e social (SANTANA, 2010, p. 93).

Diante de tantas desigualdades, o feminismo manifesta-se cada vez mais, diante de lutas e conquistas de direitos na tentativa de reconstruir a sociedade, tornando-a menos desigual. Hoje, muitas atitudes opressoras e violentas que outrora eram romantizadas, são crimes previstos na lei. Mas, a mulher ainda sofre os efeitos do patriarcado histórico. Mesmo conquistando espaço no mercado de trabalho, os afazeres domésticos ainda são responsabilidade delas. Ao fím da licença maternidade, ainda é hostilizada por decidir voltar ao emprego. Todavia, a inserção feminina no mercado de trabalho ainda é cercada por obstáculos instituídos de forma massiva e estrutural, como 
a desigualdade salarial, a falta de assistência médica, o assédio sexual, o baixo ou ausente incentivo a formação acadêmica e/ou profissional.

A ocupação de espaços que historicamente nos foi privado, como as universidades públicas, tem acrescentado copiosamente na luta feminista, pois mulheres negras e pobres estão conhecendo e construindo uma nova história, e o conhecimento é partilhado através da convivência com outras mulheres, contribuindo para a reflexão diária sobre as situações de violência de gênero sofridas diariamente, mas que são 'naturalizadas' pelxs demais.

Os caminhos que trilhamos nesta pesquisa estão fundamentados na tentativa de compreender o processo de construção de percepções em torno das relações de gênero que implicam na violência e na sexualidade, entre adolescentes de uma escola municipal em Coração de Maria, Bahia, por meio da mediação de mídias sociais. Para isso, construímos um grupo na rede social Facebook Messenger, buscando debater em torno de questões de violência de gênero entre as adolescentes, discutimos situações cotidianas de construção de gênero e sexualidade, por meio desta mídia social.

\section{TERMOS DE SERVIÇOS E POLÍTICAS DESTA CARTOGRAFIA}

Os nossos termos de serviços são baseados nas pistas cartográficas, apoiadas na Netnografia. O método cartográfico baseia-se em uma pesquisa sem delimitações pré-estabelecidas. A cartografia, como método de pesquisa-intervenção, pressupõe uma orientação do trabalho do pesquisador que não se faz de modo prescritivo, por regras já prontas, nem com objetivos previamente estabelecidos (PASSOS; BARROS, 2009). Deleuze (2006, p. 48) afirma que, "numa cartografia, pode-se apenas marcar caminhos e movimentos, com coeficientes de sorte e de perigo. [...] análise das linhas, dos espaços, dos devires".

De modo a contemplar os objetivos traçados para este trabalho, optamos por aliar a Cartografia à Netnografia, como estratégia de mapeamento do processo de construção de relações de gênero e sexualidade entre as estudantes. A Netnografia surge como algo que acompanha o crescimento da informatização na vida das pessoas, dando suporte ao processo cartográfico da pesquisa, funcionando com um elo entre pesquisadores e participantes da pesquisa.

Para Nogueira, Gomes e Soares (2012), a Netnografia é uma abordagem que propõe utilizar, na medida do possível, os mesmos critérios da pesquisa etnográfica, para pesquisas que se desenvolvam, parcial ou integralmente, no ambiente virtual. Kozinets (1998) nos lembra que, como pesquisador, envolvia-se com a comunidade a ponto de enviar mensagens ao grupo, sem sentir-se um intruso ou incomodando as pessoas com seus interesses de pesquisa. É de suma importância 
compreender que é necessário buscar interação entre o grupo criando uma rede de interações e relações.

Assim como existem as políticas de dados do Facebook Messenger, a nossa cartografia também tem as suas, baseadas nos princípios éticos da pesquisa. Para realização dessa pesquisa, as participantes assinaram um Termo de Assentimento Livre e Esclarecido (TALE), concordando com a participação. Por serem menores de 18 anos, seus responsáveis legais também assinaram um termo, o Termo de Consentimento Livre Esclarecido (TCLE), que informou os objetivos da pesquisa, a metodologia, os benefícios, arquivamento das mensagens compartilhadas no grupo do Facebook, garantia de anonimato, concordando livremente em participar ou deixar de participar a qualquer momento. Vale salientar a importância do aceite da instituição escolar para realização da pesquisa, cadastrada e aprovada pelo Comitê de Ética em Pesquisa (CEP) da Universidade Estadual de Feira de Santana (UEFS).

\section{ENCONTRANDO AMIGAS}

Estabelecidas as pistas metodológicas a serem seguidas nesse processo, chega o momento de encontrar as amigas! A pesquisa foi desenvolvida no ano 2018, tendo início no primeiro semestre letivo do mesmo ano. Inicialmente, foram convidadas a participar da pesquisa adolescentes que cursavam o oitavo e nono anos do ensino fundamental de uma escola pública da rede estadual do município de Coração de Maria, considerando a faixa etária entre 15 e 18 anos, conforme o disposto do Estatuto da Criança e do Adolescente (BRASIL, 1990), período em que as meninas passam por muitas mudanças psicocorporais e sociais, ao longo do processo de tornar-se mulher e as demandas que dele surgem (EISENSTEIN, 2005). Contudo, após o contato inicial com as participantes, muitas adolescentes não aceitaram participar da pesquisa, o que nos impulsionou a ampliar o universo de participantes, abarcando em nosso convite todas as adolescentes do terceiro e quarto ciclos do ensino fundamental, nível de ensino ofertado pela instituição escolar.

Assim, contamos com nove amigas, com idades entre 12 a 15 anos, que trilharam este caminho cartográfico, em nosso grupo focal. Para Flick (2009, p.187), os grupos focais partem de uma perspectiva interacionista e buscam mostrar o modo como uma questão é construída e alterada ao ser debatida em uma discussão de grupo.

O primeiro encontro teve como objetivo despertar o interesse das estudantes para participarem da pesquisa, para formar o grupo fechado no Facebook. Após aceitarem o convite para participar do grupo, conversamos sobre algumas regras importantes para o encaminhamento do 
trabalho, tendo como ponto principal a criação de perfis fictícios (fake), que garantiu o anonimato das participantes no decorrer da escrita. Pedimos que as estudantes não postassem nenhuma foto ou informação pessoal que pudessem identificá-las, seja no próprio grupo criado, ou além deste, já que se trata de uma rede social de abrangência mundial.

Já é sabido que a Cartografia consiste em um processo de construção processual, a qual não delimita caminhos, muito menos predetermina resultados. Logo, é um trabalho conjunto entre nós e as participantes da pesquisa, possibilitando mais liberdade de expressão de subjetividades, delineando os caminhos da pesquisa. Nesse sentido, utilizamos estratégias que promovessem tais expressões, sendo a cartografia construída a partir das opiniões que cada garota tem acerca dos assuntos discutidos em grupo.

Nesse sentido, nos utilizamos de leituras de casos (PARANÁ, 2015), que foram publicados e discutidos através do grupo formado no Facebook. Ao fim de cada leitura, instigamos as adolescentes a se posicionarem sobre o assunto, lançando perguntas que despertavam em seu interior a vontade de se expressar com sinceridade, num processo contínuo de escuta-leitura. Esses casos foram escolhidos baseados em situações cotidianas que ocorrem no cotidiano de adolescentes/mulheres, dentro e fora da escola.

\section{ABRA UMA CONTA! É GRATUITO E SEMPRE SERÁ}

A idealização das personagens para criação do perfil fake instigou a criatividade e a participação ativa das adolescentes no desenvolvimento do trabalho, desde o início, configurando-se como uma estratégia que pode ser utilizada nas disciplinas escolares para motivarem a participação das/dos estudantes nas atividades, utilizando metodologias que façam da/do discente protagonista em seu aprendizado, buscando e construindo conhecimento sem menosprezar o que é aprendido além das vivências escolares.

Segundo Fernandes e Santos (2007), se a escola não inclui a Internet na educação das novas gerações, ela está na contramão da história, alheia ao espírito do tempo e produzindo a exclusão da cibercultura, pois virtualmente também se aprende, além de possuir uma quantidade ilimitada de informações, permite a flexibilidade no uso, podendo ser consultado e utilizado como recurso em qualquer lugar e a qualquer momento.

As Tecnologias da Informação e Comunicação (TICs) podem ser utilizadas como uma estratégia para aproximar os estudantes das atividades e conteúdos escolares, principalmente se consideradas as grandes mudanças que vêm ocorrendo nos processos de ensino e aprendizagem, 
motivadas justamente pelo desenvolvimento de novas ferramentas e tecnologias (MATTAR, 2014). Essas tecnologias permitem aos estudantes uma construção de conhecimento colaborativa, na qual os professores podem ter o seu papel de mediadores de conhecimento ampliado, ajudando na construção do mesmo de forma crítica, com amplos caminhos a serem seguidos. Além disso, pode tornar-se um trabalho coletivo estreitando as relações pessoais entre os participantes da rede. O ensinar e o aprender acontecem em uma interligação simbiótica, profunda e constante entre os mundos físico e digital (MORAN, 2015).

O Facebook Messenger é uma rede social que ganhou espaço na vida das pessoas, principalmente de estudantes. Tal fato pode estar atrelado à grande diversidade de ferramentas e possibilidades que esta rede social possui e permite, a fim de manter pessoas conectadas. Patrício e Gonçalves (2010) afirmam que as redes sociais representam uma nova tendência de partilhar contatos, informações e conhecimentos. O Facebook é uma das redes sociais mais utilizadas em todo o mundo para interagir socialmente.

As ferramentas disponíveis no Facebook tornam a rede social um potencial espaço informal para o ensino e a aprendizagem. A maioria das e dos estudantes passa boa parte do seu tempo livre na Internet e no Facebook, então desenvolver atividades pedagógicas nesse espaço virtual pode culminar em excelentes resultados para a construção individual e coletiva de conhecimento.

\section{LINHA DO TEMPO}

Após criarmos nossos perfis fakes e nos tornarmos amigas, criamos o grupo para nossa discussão, nomeado de "Eu tenho uma opinião!”. O primeiro caso postado no grupo de discussão foi o "Sexting", que trata sobre a divulgação de conteúdo com conotação sexual de uma garota de 16 anos enviado para seu namorado via Whatsapp, sendo divulgado no grupo das amigas e amigos da escola. O segundo caso é "Violência de Gênero na Sala de Aula", que trata sobre ofensas machistas sofridas por uma garota, feitas por um colega da classe. O terceiro é intitulado de "Violando o direito de livre expressão da orientação sexual", que trata da relação afetiva entre duas garotas, que ao serem descobertas sofrem ameaças e agressões verbais de colegas da escola motivados pela atitude de um pai descontente com o relacionamento das adolescentes (PARANÁ, 2015).

\section{Caso 01: Sexting (Publicado em 17 de julho de 2018)}

O caso Sexting (FIGURA 01) trata do compartilhamento de conversas com conteúdos sexuais de um casal heterossexual, da escola. 
Ao abordar as práticas de Sexting entre adolescentes e como estas vem sendo evidenciadas na literatura empírica, Barros e Ribeiro (2016), apontam para seu papel na atualização do dispositivo de sexualidade, atuando na regulação e controle dos corpos adolescentes, compreendidos em geral em sua essencialidade, vivenciados indiferenciadamente pelos sujeitos.

Embora o sexting seja realizado por sujeitos de diversas faixas etárias, esta pesquisa tem como foco de estudo o sexting na adolescência. Autores como Willard (2013) entendem que a prática do sexting na adolescência estaria ligada a características próprias dessa fase, tais como: a impulsividade, a explosão hormonal e a incapacidade biológica dos/as adolescentes de preverem as potenciais consequências de suas ações. Tal visão está atrelada a uma ideia biologicista da adolescência a, a qual é entendida como uma essência; ou seja, algo natural, que é vivenciado por todos os sujeitos da mesma forma. (BARROS; RIBEIRO, 2016, p. 413)

Dado o caráter regulador do sexting no dispositivo da sexualidade, nos importou compreender como as adolescentes em nosso grupo conferem sentidos a estas práticas e como constroem atualizações ou demarcações de outras relações de gênero possíveis diante do compartilhamento e vazamento de mensagens erótico-sensuais na Internet.

Figura 01: Post do Caso 01.

\begin{tabular}{|c|c|}
\hline \multicolumn{2}{|l|}{$\begin{array}{l}\text { Valentina Soares } \\
17 \text { de julho de } 2018\end{array}$} \\
\hline \multicolumn{2}{|l|}{ Caso 1: Sexting } \\
\hline \multicolumn{2}{|c|}{$\begin{array}{l}\text { Leila é uma menina adolescente de } 16 \text { anos que namora com Felipe } \\
\text { Eduardo, com } 17 \text { anos de idade. Leila é uma menina super antenada nas } \\
\text { redes sociais, utilizando todos os recursos tecnológicos de que dispõe para } \\
\text { fazer novas amizades e divulgar fatos de sua vida pessoal. Seu namoro } \\
\text { com Felipe Eduardo é amplamente socializado nas redes sociais, fato que } \\
\text { dá margem para os pitacos das amigas e amigos. Leila e Felipe trocaram } \\
\text { mensagens pelo Whatsapp e o conteúdo tinha conotação sexual e foi } \\
\text { divulgado no grupo de amigas e amigos do Colégio. Isto gerou um enorme } \\
\text { constrangimento para Leila, pois muitas pessoas a atacaram de maneira } \\
\text { preconceituosa, dizendo que ela não poderia expor sua intimidade desta } \\
\text { maneira. Para Felipe, houve maior condescendência, pois para a maioria } \\
\text { dos meninos e meninas ele é homem. }\end{array}$} \\
\hline $\begin{array}{l}\text { - O que vocês acham sot } \\
\text { entre Leila e o Namorado } \\
\text { - Vocês concordam que } \\
\text { punindo Leila e isentand }\end{array}$ & $\begin{array}{l}\text { ento do conteúdo da conversas } \\
\text { la agiram de forma correta } \\
\text { Porque? }\end{array}$ \\
\hline (1) 4 & 35 comentários Visualizado por 8 \\
\hline 글 Curtir & $\square$ Comentar \\
\hline
\end{tabular}

Quando perguntamos suas opiniões acerca do compartilhamento das conversas, percebemos que todas as adolescentes partilhavam a mesma opinião da participante Elisabeth Monseha ${ }^{1}$

\footnotetext{
${ }^{1}$ Optamos por apresentar os nomes dos perfis fictícios em itálico.
} 
(FIGURA 02). Além disso, perguntamos se elas concordavam com a forma que os colegas da escola agiram, punindo Leila e isentando Felipe da culpa.

Figura 02: Opiniões das adolescentes sobre o caso 01.

Elisabeth Monseha $\cdot$ Eu acho isso anti ético.Por que independente de ela ter mandado ou não ninguém tem o direito de espalhar

•Não.Pois na maioria das vezes cupam os meninos.Mas nenhuma menina é obrigada a estar mandando essas coisas. Se ela mandou foi por que ela quis. Foi a vontade dela.

\section{Curtir - Responder - 14 sem}

(8) Valentina Soares Elisabeth Monseha, pra você o que é uma coisa antiética?

$$
\text { Curtir - Responder - } 14 \text { sem }
$$

(1) Elisabeth Monseha Uma falta de educação, respeito.

$$
\text { Curtir - Responder - } 14 \text { sem }
$$

Bridget Evans Eu acho isso anti ético, por que independente dela ter mandado ou não ninguém tem o direito de espalhar esses tipo de coisas

Obs: ela não sabia que iriam expor as conversas

Curtir - Responder - 14 sem

6. Elisabeth Monseha Concordo

Curtir-Responder - 14 sem

Cristina Yang Acho isso antiético pq independente de ela ter mandado ou não ela e namorada dele não era pra ele espalhar nada em grupo de amiguinhos

Não, pq na maioria das vezes às pessoas culpam mais os meninos , mas as meninas também tem a opção de mandar ou não , foi a vontade dela

Curtir-Responder-14 sem

Durante o bate-papo com as garotas, percebemos que concordavam que o compartilhamento das mensagens do casal (Leila e Eduardo) foi uma atitude "antiética" de quem o fez, baseando-se no fato que "ninguém tem o direito de espalhar esses tipo de coisas".

Essa é mais uma forma de violentar simbolicamente uma mulher, pois está ferindo um direito garantido, o direito a privacidade. Atitudes assim despertam um questionamento acerca do uso das redes sociais: como elas têm sido utilizadas para fortalecer as formas de violência de gênero? 
Beatriz Accioly Lins (2016) nos leva a refletir sobre tal questionamento, ao discorrer sobre a chamada "pornografia da vingança", termo cunhado por militantes feministas, em denúncia a esta faceta virtual da violência de gênero, em que a divulgação não autorizada de mensagens de teor erótico-sensual "vazam" corriqueiramente nos ambientes virtuais:

Após tomar conhecimento dos casos envolvendo as adolescentes, realizei uma rápida pesquisa na internet que resultou em uma enorme quantidade de notícias e textos de sites e blogs feministas sobre o assunto, nos quais a "pornografia de vingança" era apresentada como uma nova forma - propiciada pelos avanços nas tecnologias de informação - de perpetuar discriminações e violências contra mulheres, posto que, uma vez espalhados pela rede, tais conteúdos trariam como consequência uma espécie de linchamento moral às vítimas, que seriam julgadas e atacadas por seus comportamentos sexuais. (LINS, 2016, p. 249)

Diante deste "vazamento" de mensagens que expõem as adolescentes, como as meninas de Coração de Maria, participantes de nosso estudo, se posicionam? Se, por um lado, as meninas compreendem esta atitude como "antiética", por outro expõem que "foi vontade dela" enviar as mensagens "mesmo sabendo que é errado", como claramente expressam Beatriz Araújo e Jennifer Santos (FIGURA 03).

Figura 03: Opiniões de Beatriz Araújo e Jennifer Santos sobre o caso 01

Beatriz Araújo eu acho quer isso e errado muita das vezes as pessoas julgar a menina mas nem uma para fala com ela mas foi a vontade dela envia a foto para o seu namorado mesmo ela sabido quer e errado. não porque não cabe as pessoas julgarem a ela porque não ser sabir do dia da manhã foi errado mas foi a vontade dela e ela não saberia quer ele faria isso com ela e ela estava confiado nele

Curtir - Responder - 13 sem

Jennifer Santos Não.Pois na maioria das vezes culpam os meninos.

Más nenhuma menina é obrigada a manda fts sexuais, Se ela mandou foi por que ela quis,Ninguém é obrigado a

nada.Foi a escolha dela!

Curtir - Responder - 13 sem

Importante destacar que não apenas o vazamento da mensagem é considerado "errado" por algumas, mas o próprio compartilhamento da mensagem com o namorado parece, para algumas adolescentes, um atitude "errada". Neste sentido, compreendemos o papel do sexting na atualização do dispositivo de sexualidade entre as adolescentes (BARROS; RIBEIRO, 2016). Existe no bate- 
papo entre as meninas um discurso implícito de responsabilização e controle de corpos por parte das meninas, disciplinando corpos, educando-os como corpos femininos (LOURO, 2000a).

Retomando o bate-papo, quando perguntadas se é certo ou errado enviar conteúdos sexuais para seu namorado, as palavras confiança e intimidade surgem como algo imprescindível para essa tomada de decisão (Figura 04). Para Bridget Evans, a intimidade é algo que é construído após um longo período juntos, e a partir daí há confiança suficiente para compartilhamentos de tal natureza. Em outras falas, há concepções semelhantes:

Figura 04: Conversando com Bridget Evans e Beatriz Araújo sobre o caso 01.

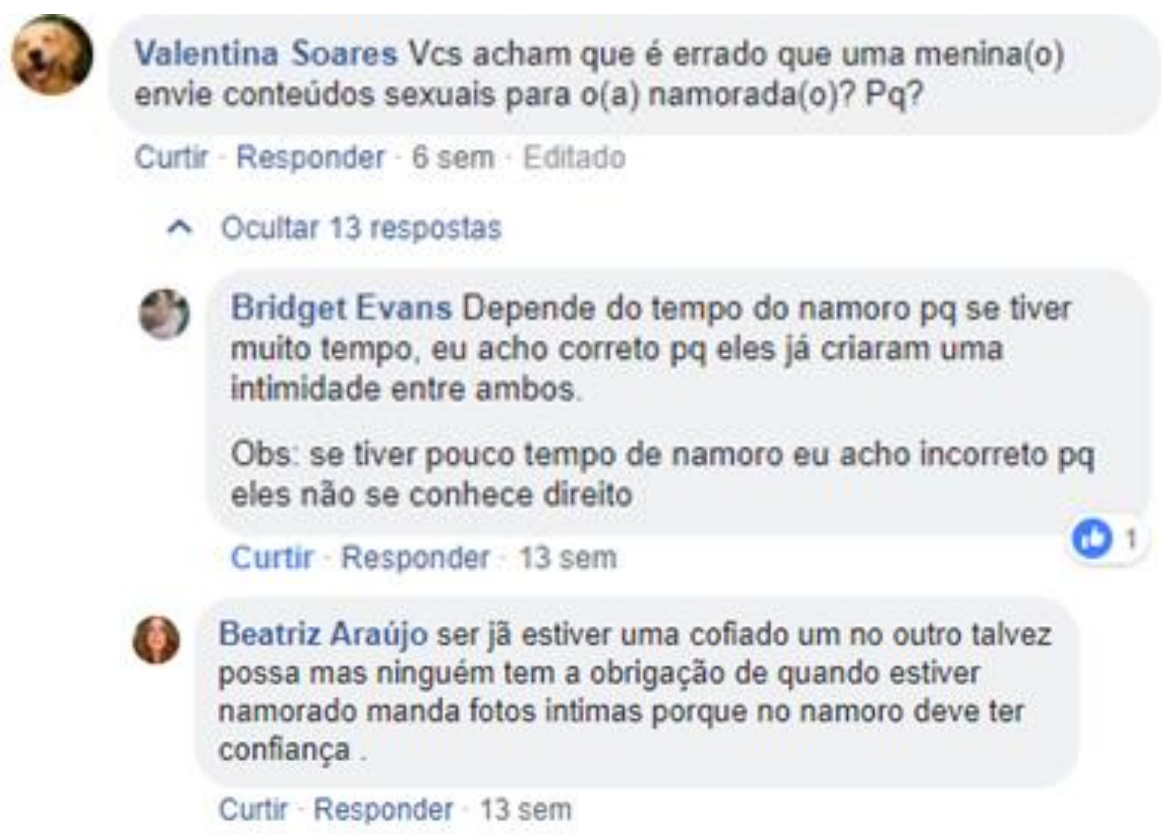

Briget Evans e Beatriz Araújo, quando discordam das trocas de sexting em suas falas, não citam exceções, isto é, tanto menino quanto menina não devem trocar conteúdos que possuam conotação sexual, colocando apenas como fator crucial a intimidade e a confiança no outro. Mas, durante a conversa, a maioria das participantes apontava a garota Leila como única responsável pelo envio das mensagens com conotação sexual, por exemplo: "Mas se for da vontade da menina mandar né", "Eu não acho certo, mas se ela tiver confiança nele e se ela quiser mandar a escolha e dela...”.

Os discursos produzidos pelas adolescentes, de um modo geral, retratam as relações de gênero que se constroem e se reproduzem sociohistoricamente, por meio de relações de poder e saber, em que meninos e meninas são ensinados e modelados segundo padrões hegemônicos (LOURO, 2000a), nos quais “meninas aprendem a preservar e resguardar a sua sexualidade, já os 
meninos são estimulados a sentirem prazer e a manterem relações sexuais desde cedo" (BARROS; RIBEIRO, 2016, p. 431).

Neste sentido, as adolescentes em nosso grupo forjam um discurso de penalização do sexting por parte da menina, que se torna responsável não apenas pelo compartilhamento da mensagem, mas também por seu "vazamento", já que "não deveria ter enviado, se não há confiança no namorado". Mas, em nossos padrões socioculturais hegemônicos, como uma menina pode confiar em meninos, se há uma naturalização do papel da mulher na preservação de sua sexualidade? Assim, ao praticarem o sexting, são as adolescentes as que mais sofrem violências, o que nos possibilita verificar algumas desigualdades em relação às questões de gênero.

\subsection{Caso 02: Violência de gênero na sala de aula (publicado em 08 de agosto de 2018)}

O segundo caso que debatemos, intitulado de "Violência de Gênero na sala de aula", trata-se de uma discussão proposta por uma professora de Sociologia sobre instituição familiar e relações de gênero, na qual surge uma polêmica envolvendo ocupações atreladas ao gênero e relações de poder sobre sujeitos, que nesse caso é entre o poder do homem sobre a mulher (Figura 05).

\section{Figura 05: Post do Caso 2.}

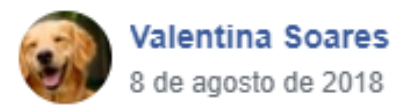

Na aula de Sociologia, a professora Frida, abordava a temática sobre a Instituição Familiar e as relações de gênero, junto aos estudantes da turma do $1^{\circ}$ ano do Ensino Médio do Colégio Estadual Chiquinha Gonzaga. Começou um tumulto por conta de uma discussão entre dois colegas de sala. Rosa, uma adolescente de 14 anos e Rodrigo da mesma idade, discutiram de maneira acirrada. Isto porque, Rodrigo não aceitou de Rosa uma defesa sobre os direitos das mulheres e teceu um comentário ofensivo à colega, dizendo que: "lugar de mulher é na cozinha, esquentando a barriga no fogão e esfriando no tanque".

- Quais sentimentos você sentiu ao ler a frase dita por Rodrigo? "Lugar de mulher é na cozinha, esquentando a barriga no fogão e esfriando no tanque".

- Em uma família, deve existir tarefas e/ou responsabilidades atribuídas em consequências do gênero?

- Em sua casa, como acontece?

Jennifer Santos e Elisabeth Monseha

41 comentários Visualizado por 8

C Curtir Comentar


No que tange às relações de poder, destacamos o pensamento de Vicente (2015) que, inspirando-se nos contributos teóricos de Foucault, afirma que:

o poder atua não apenas reprimindo - essa que até então era, de forma geral, a postulação dos estudos acerca do poder - e que o poder não é apenas uma instância que diz não, mas o poder produz, é produção de mundos e de relações complexas, assim como é um mecanismo de produção de subjetivação (VICENTE, 2015, p. 87).

Assim, o poder pode ser exprimido de várias formas, e uma das mais singelas maneiras de exercer e ser resultado desse processo, é o poder vivido (tanto para quem o detém, quanto para quem esta sujeito ao mesmo) na forma simbólica e sutil, em que as relações de opressão são mascaradas com discursos e práticas e perpetuadas em toda uma comunidade. Tomando estes viés teórico, iniciamos a discussão no grupo com a frase pronunciada por Rodrigo a sua colega de turma: "Lugar de mulher é na cozinha, esquentando a barriga no fogão e esfriando no tanque", com a intenção de compreender as opiniões das adolescentes ao lê-la (Figura 06).

Figura 06. Opiniões de Elisabeth Monseha, Beatriz Araújo e Bridget Evans sobre o caso 02.

Elisabeth Monseha Eu já vivi situações onde pessoas próximas de mim disseram isso. Eu defendi as mulheres é claro.Por que não importa se é do gênero feminino que não pode isso não pode aquilo...... Mulher tem o mesmo direito dos homens.

-Sentimento de indignação, pois a MULHER tem o direto de exercer a profissão que ela quiser.Seja Juiza, jogadora de futebol, arquiteta, etc... Independente de gênero.

Beatriz Araújo isso quer rodrigo dizer e muito errado porque lugar de mulher e na onde ela quer esta nos mulheres podemos fazer 0 quer quiser ir na onde queremos, sair para onde queremos, trabalha onde queremos, não muda nada nos mulheres somos guerreira sim isso quer mulher não poder fazer as mesma coisas quer os home e besteira nos somos mulheres e queremos ser respeitada.

Curtir - Responder $\cdot 9$ sem

Bridget Evans Ueee eu iria me senti ofendia, pelo fato corrido, pois em pleno século XXI as mulheres estão ocupando cargos que deveria ser dos homens Moral da história: as mulheres podem ficar, fazer o que elas querem

Curtir - Responder - 7 sem 
Percebemos que há nos argumentos a certeza em saber que podem ocupar qualquer espaço, e que o gênero não é um determinante para isso, pronunciando palavras que anseiam liberdade. Sim, liberdade! Libertar-se do poderio histórico dos homens sobre as mulheres, dos costumes de uma sociedade patriarcal muito bem estabelecida em nossa sociedade que vem nos subjetivando há longos séculos. Não é fácil, requer uma luta diária, pois esse patriarcado configura-se também em diversas formas de violência de gênero, psíquica, financeira e física, privando-a da autonomia. Para Butler (2011), a sujeição é o processo em que nos tornamos subordinados ao poder e ao mesmo tempo devimos sujeitos sociais. O sujeito se constrói ao passo dessa subordinação, isto é, a subordinação acaba sendo parte integrante da formação do sujeito.

Dando continuidade à conversa (Figura 07), tentamos aproximar o relato do caso lido com a vida e a experiência familiar de cada menina, questionando se em uma família devem existir tarefas e/ou responsabilidades atribuídas em consequência do gênero.

\section{Figura 07: Conversa com Elisabeth Monseha sobre o Caso 02}

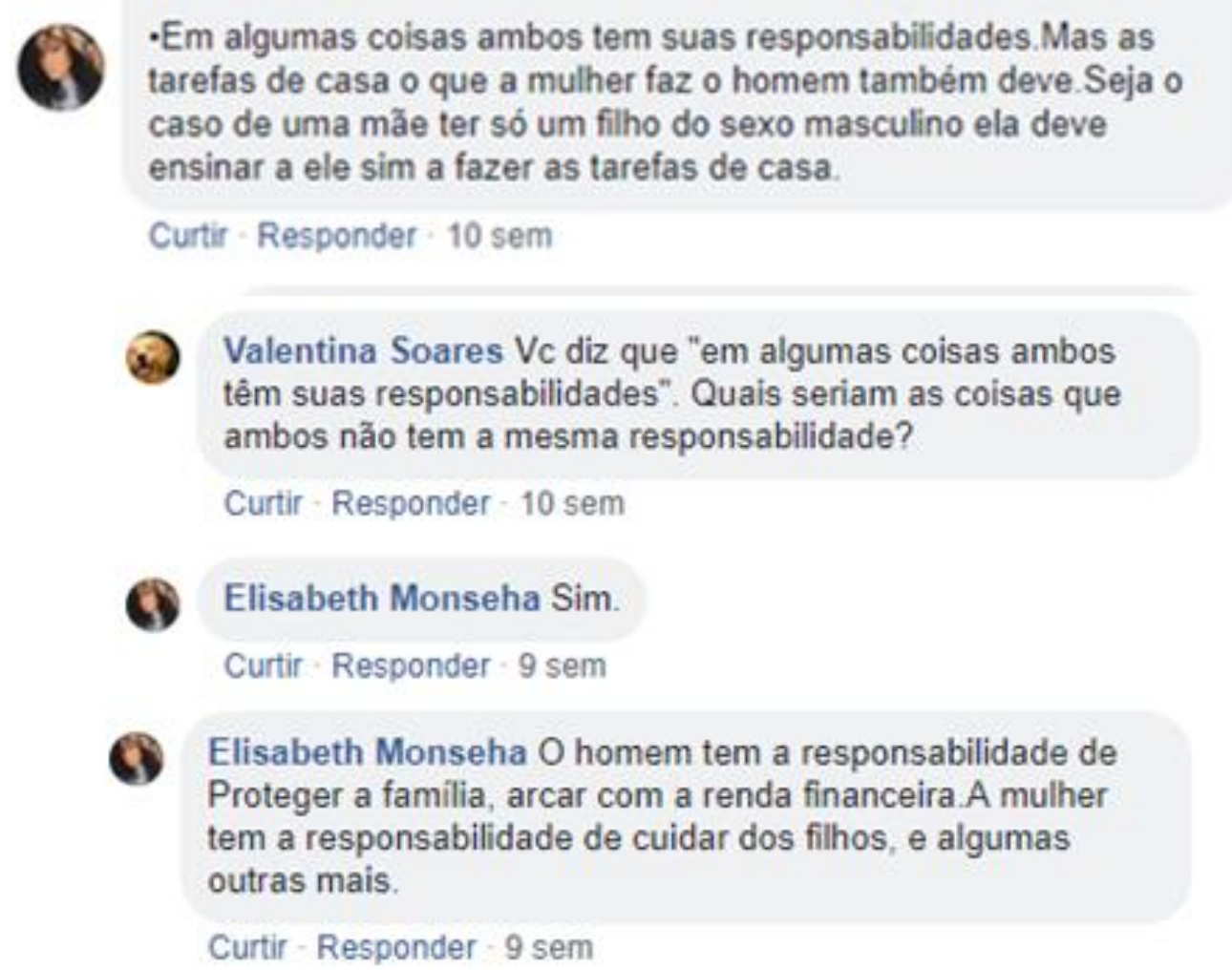

As concepções são construídas principalmente pelas vivências pessoais. A vivência de constituição de família da autora da personagem (Elisabeth Monseha) é de uma mãe que é a chefe da família composta por um filho e uma filha (Elisabeth), logo esse é o exemplo de vida que ela tem, na qual a mãe é a única que exerce com responsabilidade a função de ensinar. 
No início da conversa, Elisabeth apresenta argumentos sólidos quanto à contrariedade das responsabilidades serem atribuídas em uma família de acordo com o gênero, mas em sua fala há evidências de uma constituição social baseada no patriarcado.

Em seus comentários, Beatriz Araujo (Figura 08) enaltece a importância da mulher sentir-se bem onde deseja estar, sendo respeitada por suas escolhas e também traz a concepção de que o homem pode ajudar na tarefa de casa, isto é, não é um dever ou responsabilidade dele e por isso ele só ajuda. Isso é o reflexo de uma conformação cultural em que homens não cuidam dos afazeres domésticos, pois 'é coisa de mulher', e se o faz, “é um homem bonzinho por que ajuda a esposa”. São pensamentos dessa natureza que, ainda hoje, regem a nossa sociedade.

\section{Figura 08: Conversa com Beatriz Araújo sobre o Caso 02}

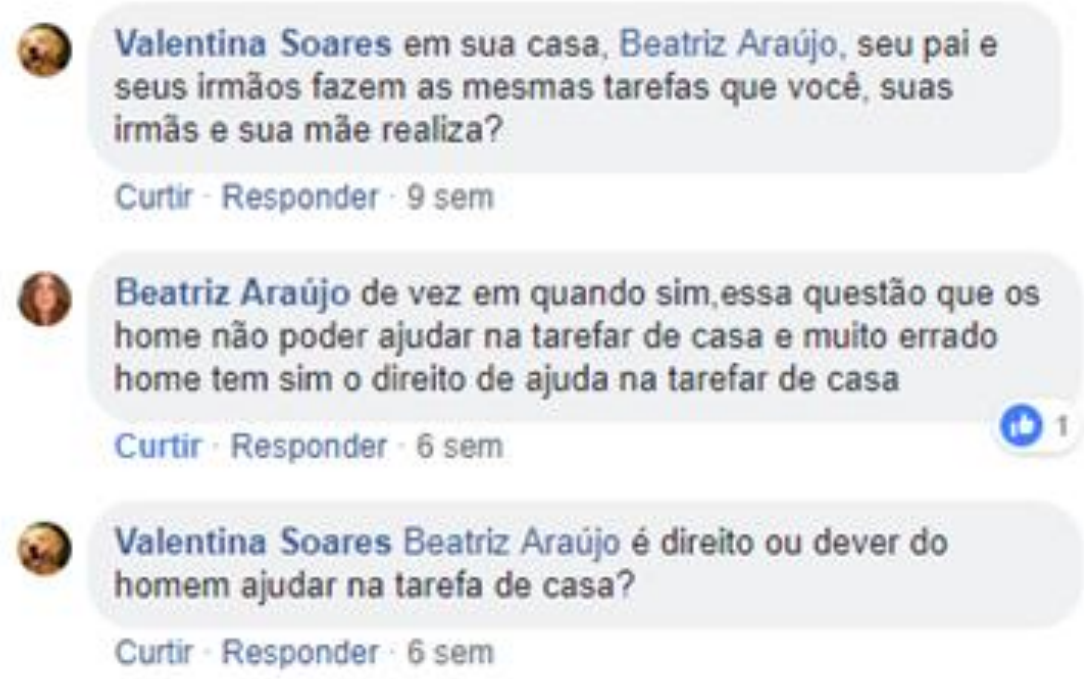

Historicamente, foram sendo atribuídos papeis e responsabilidades aos integrantes de uma família de acordo com o gênero, sob domínio patriarcal. Como afirma Narvaz e Koller (2006), com a descoberta da agricultura, da caça e do fogo,

as comunidades passaram a se fixar em um território. Aos homens (predominantemente) cabia a caça, e às mulheres (também de forma geral, embora não exclusiva), cabia o cultivo da terra e o cuidado das crianças. Uma vez conhecida a participação do homem na reprodução e, mais tarde, estabelecida a propriedade privada, as relações passaram a ser predominantemente monogâmicas, a fim de garantir herança aos filhos legítimos. O corpo e a sexualidade das mulheres passou a ser controlado, instituindo-se então a família monogâmica, a divisão sexual e social do trabalho entre homens e mulheres. Instaura-se, assim, o patriarcado, uma nova ordem 
social centrada na descendência patrilinear e no controle dos homens sobre as mulheres (NARVAZ; KOLLER, 2006, p.50).

Estas atribuições de papéis e responsabilidades estão presentes nos discursos das adolescentes, o que parece reforçar o reprodução social de relações de gênero baseadas no patriarcado nos contextos em que as meninas se inserem. Esta questão torna-se evidente na conversa com Elizabeth Monseha, em que há evidências de uma constituição social baseada no patriarcado, "O homem tem a responsabilidade de Proteger a família, arcar com a renda financeira. A mulher tem a responsabilidade de cuidar dos filhos, e algumas outras mais".

\subsection{Caso 03: Violando o direito de livre expressão da orientação sexual (publicado em 30 de agosto de 2018)}

O caso intitulado "Violando o direito de livre expressão da orientação sexual" aborda uma situação ocorrida em uma escola, na qual um pai de uma colega vê duas alunas se beijando e se reporta indignado na diretoria. Os comentários são espalhados na turma, causando a intimidação das adolescentes a ponto das mesmas ficarem com medo de voltar à escola (Figura 09). 


\section{Figura 09: Post do Caso 03}

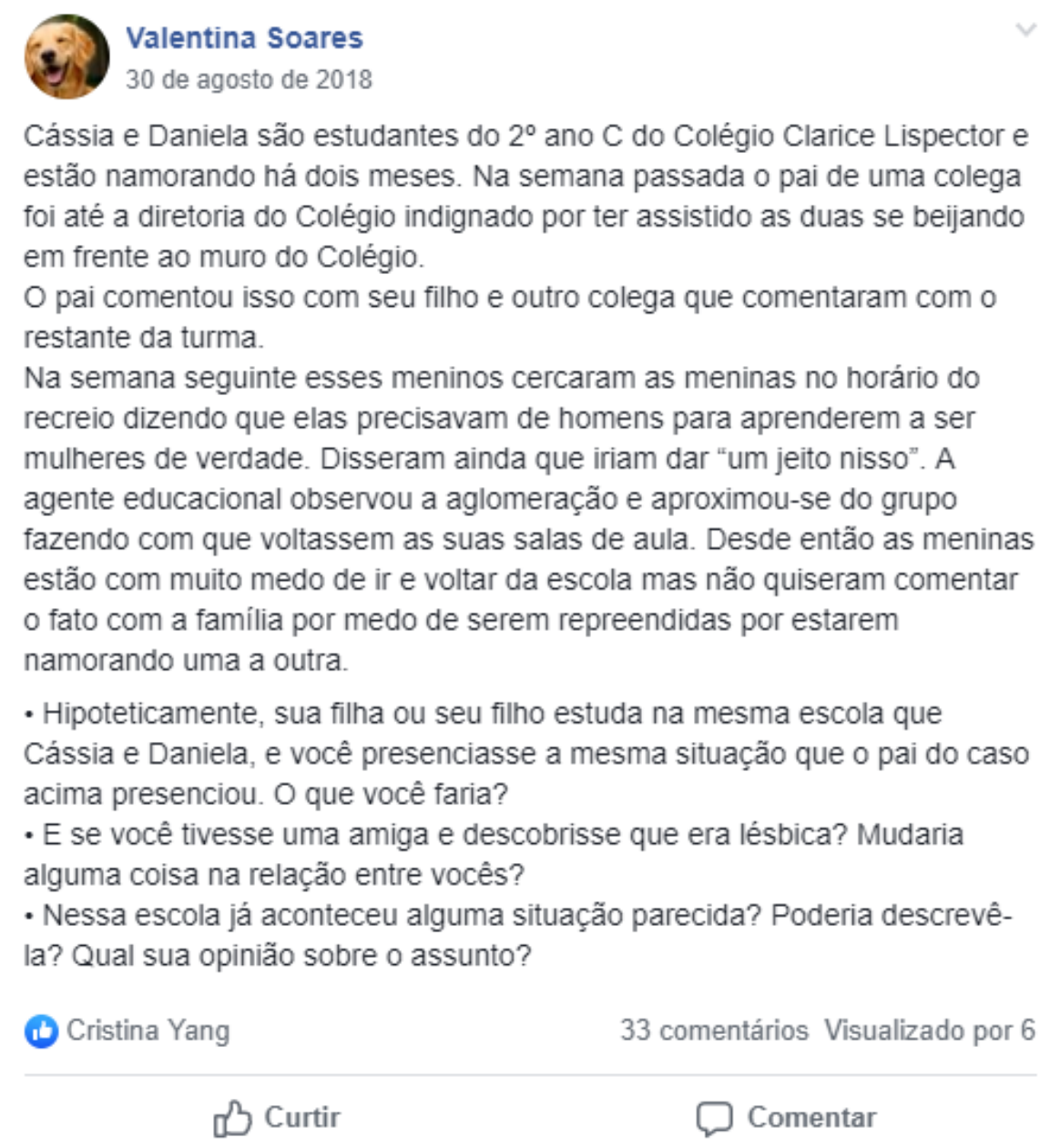

As perguntas foram direcionadas desta maneira para abordar as possíveis situações que podem ter acontecido, ou não, e como elas se posicionariam diante disso. Quando perguntadas sobre qual posição assumiriam caso presenciassem a mesma situação que o pai presenciou, as adolescentes relataram nunca ter presenciado tal situação e, de modo geral, não saberiam qual seria sua reação, contudo a maioria não demonstrou animosidade com relação ao caso, conforme exposto na Figura 10. 
Figura 10: Opiniões das adolescentes com relação ao Caso 03.

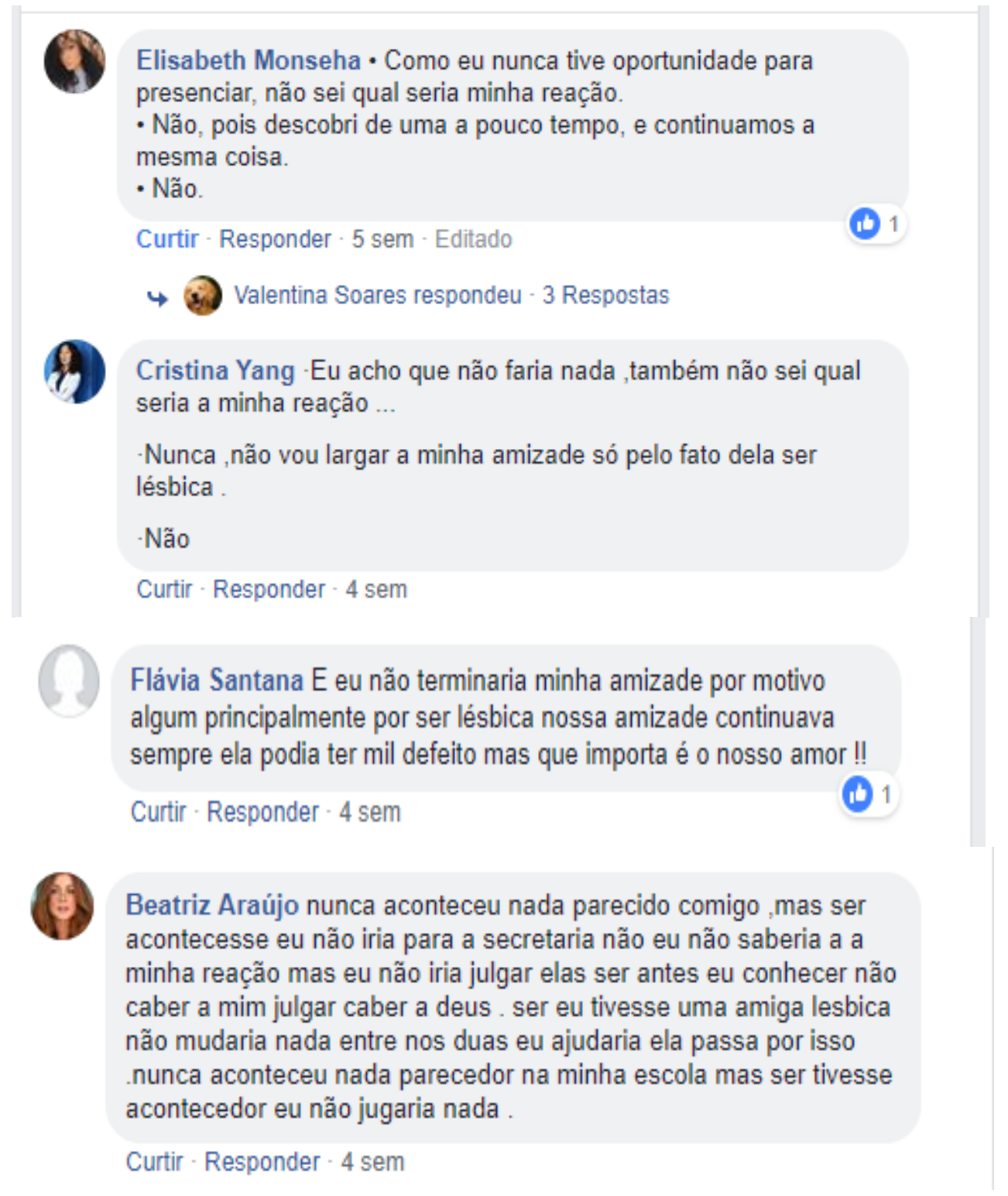

A pergunta seguinte questiona a possibilidade de uma amizade ser afetada caso elas descobrissem que a suposta amiga fosse lésbica. Elisabeth Monseha disse com firmeza que "Não pois descobri de uma a pouco tempo, e continuamos a mesma coisa". Cristina, Flávia, Beatriz e Jennifer deixaram claro que não terminariam a amizade por isso.

"Mas ser acontecesse eu não iria para a secretaria não eu não saberia a minha reação mas eu não iria julgar elas ser antes eu conhecer não caber a mim julgar caber a deus" (Beatriz Araújo). Note que o argumento utilizado por Beatriz para justificar a sua opinião, reflete, provavelmente, uma educação cristã, em que não é incumbência dela (ou de qualquer outra pessoa) julgar a vida de outra pessoa, e talvez seja por isso que ela escreveu “eu não iria julgar elas ser antes eu conhecer", 
expressando, implicitamente, que cada indivíduo vive em realidades diferentes e que se ela não conhece, ela não deve criticá-la.

De modo diferente das demais adolescentes, Maria Flor foi sincera e direta, mas não quis argumentar o seu posicionamento (FIGURA 11). Ao afirmar que "terminaria a minha amizade" caso descobrisse que a sua amiga fosse lésbica, e não mais se posicionou no grupo, nem continuou o bate-papo. Respeitando os princípios éticos, não tentamos conversar com ela fora do grupo, pois concordamos que só conversaríamos sobre os casos no grupo.

Figura 11: Opinião de Maria Flor com relação ao Caso 03

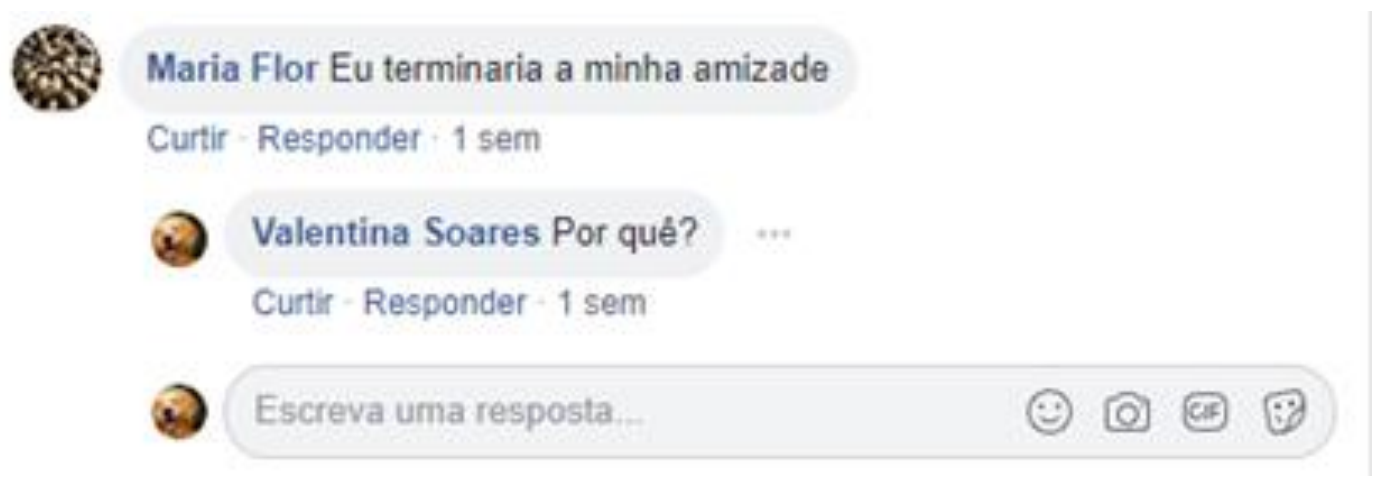

Em outro momento da conversa, Elisabeth Monseha afirma que seria uma "surpresa total" ter uma filha lésbica, de modo a não saber como "reagiria", já que ela havia (hipoteticamente) idealizado uma menina. O comentário de Elisabeth assemelha-se ao exemplo da naturalização dos processos de construção da identidade decorrentes da repetição das normas constitutivas seria a interpelação médica.

Nesse caso, através do procedimento da ultra-sonografia, transforma-se o "bebê" antes mesmo de nascer em "ele" ou "ela", na medida em que se torna possível um enunciado performativo do tipo: "é uma menina”! A partir desta nomeação, a menina é "feminizada" e, com isso, inserida nos domínios inteligíveis da linguagem e do parentesco através da determinação de seu sexo. Entretanto, essa "feminização" da menina não adquire uma significação estável e permanente. Ao contrário, essa interpelação terá que ser reiterada através do tempo com o intuito de reforçar esse efeito naturalizante (ARÁN; PEIXOTO JÚNIOR, 2007, p. 134).

A sua fala é comum à de grande maioria de mães, pais e familiares quando relatam a "descoberta" da orientação sexual de seus filhos e filhas que divergem do esperado, que seria o sexo biológico como determinante da atração afetiva, que seria pelo sexo oposto. 
Para Jennifer Santos, não há dúvidas, ser lésbica é uma escolha. E para ela, esta é baseada no fato de "ela se sente bem, com uma pessoa do mesmo sexo que ela.". E que pelo fato de ser uma escolha, a qualquer momento, pode voltar a se relacionar com homens. Em primeira instância, relacionamos a concepção de Jennifer sobre a lesbianidade como uma confusão de conceitos entre lésbica e bissexual. Mas, compreendemos que as relações afetivas não devem ser somente explicadas como algo biológico e "consciente", mas que os caminhos trilhados por essa pessoa, suas vivências e experiências é que levam-nas a trilhar caminhos, homossexuais ou heterossexuais.

A maioria das estudiosas e estudiosos considera que a sexualidade supõe ou implica mais do que corpos, que nela estão envolvidos fantasias, valores, linguagens, rituais, comportamentos, representações mobilizados ou postos em ação para expressar desejos e prazeres. Haveria de se compreender a sexualidade como um constructo histórico, como sendo produzida na cultura, cambiante, carregada da possibilidade de instabilidade, multiplicidade e provisoriedade (LOURO, 2007).

É importante compreender que sexualidade vai além da composição química e biológica dos corpos, e sim, é resultado da inserção e da modelagem e construção desse indivíduo dentro de um contexto social e histórico, no qual a cultura tem forte contribuição e funciona como uma demarcação social (LOURO, 2000a). Nesse sentido, o corpo não pode ser visto como algo imutável e igual entre todas e todos. O corpo será desenvolvido e modelado de acordo com tais perspectivas sociais e culturais, sendo vivido e experimentado de maneiras e formas diferentes, logo estará em constantes mudanças, decorrentes das mudanças culturais, por isso o corpo se constitui em uma identidade concreta, em que demonstra, mesmo de forma singela, os ideais de vida da pessoa (LOURO, 2000b).

O poder que foi construído historicamente junto com a humanidade, colocou o/a heterossexual como um/a humano/a melhor, por vezes superior aos que não se adequam ao padrão heteronormativo. Padrões que ditam masculinidade e feminilidade, que devem ser restritos aos meninos/homens e meninas/mulheres, respectivamente não devem ser seguidos pelo sexo oposto (LOURO, 1998). E algum comportamento que não é conveniente a esses padrões são submissos a essas relações de poder, que foram estabelecidas levando em conta o que é verdade para a maioria, que dissemina e investe nesse poder como um saber em uma sociedade, como nos faz refletir Michel Foucault:

Nenhum saber se forma sem um sistema de comunicação, de registro, de acumulação, de deslocamento, que é em si mesmo uma forma de poder, e que está ligado, em sua existência e em seu funcionamento, às outras formas de poder. Nenhum poder, em 
compensação, se exerce sem a extração, a apropriação a distribuição ou a retenção de um saber. Nesse nível, não há o conhecimento, de um lado, e a sociedade, do outro, ou a ciência e o Estado, mas as formas fundamentais do "saber-poder" (FOUCAULT, 1997, p. 19).

Essas são situações que exemplificam as "verdades" estabelecidas numa sociedade machista e heteronormativa, que só admite os padrões estabelecidos por ela. Sendo assim, a produção dos saberes e a produção "da verdade" estão diretamente ligadas ao exercício de poder, da mesma forma que o poder não pode ser exercido sem a produção desses saberes.

\section{COMEMORANDO UM ANO DE AMIZADE NO FACEBOOK}

Enquanto conversávamos com as adolescentes, pudemos perceber que, por vezes, as adolescentes reproduzem atitudes e comentários machistas, talvez como uma forma de resistência que elas encontram para sobreviver em uma sociedade que nos hostiliza e põe inúmeros tipos de barreiras em nosso caminho, e para superá-las, muitas vezes é preciso que deixemos a sociedade acreditar que estamos moldadas a tal configuração machista patriarcal, daí muitas vezes opiniões que, a princípio, possam parecer contraditórias de algumas adolescentes, expostas no grupo Facebook Messenger.

O primeiro caso, o Sexting, despertou nas participantes o sentimento de revolta e acusação. Se revoltaram com o "vazamento" das mensagens compartilhadas entre os namorados, considerando a atitude como "antiética". Mas, em contrapartida, carregam em seu discurso a culpabilização da mulher por isso ter acontecido.

O segundo caso, "Violência de Gênero em Sala de Aula", foi escolhido com o intuito de provocar uma reflexão em sua vida pessoal ou familiar, a ponto de levá-las a externar opiniões sobre situações que elas possam ter vivenciado. Neste caso, houve situações que foram contadas pelas adolescentes como reais, vividas por elas ou por alguém bem próximo. Além disso, provocou nelas o desejo de observar a própria família, talvez como nunca observaram antes, a respeito da divisão e atribuição de tarefas.

O terceiro caso do nosso grupo virtual retrata a violência de gênero sofrida por lésbicas, a partir do qual abordamos questões que envolvem possíveis situações cotidianas vivenciadas pelas adolescentes, no sentido de compreender seu posicionamento frente à construção da identidade sexual e as relações de poder envolvidas nestas construções. De modo geral, as adolescentes não foram afetadas pelo caso, afirmando não ter vivenciado situações semelhantes e não saber como se 
posicionar frente a esta questão, a não ser pelo posicionamento de uma adolescente que, ao se posicionar contrariamente à amizade, deixou de participar das discussões do grupo.

Ao longo das discussões em torno dos três casos, ficou evidente, pelos relatos apresentados, que as percepções em torno das relações de gênero e da violência de gênero expressam uma concepção naturalizante do gênero feminino, que impõe à mulher o papel de preservação de sua sexualidade e de seus papéis sociais, fruto de relações de saber e poder historicamente constituídas em nossa sociedade.

Esta cartografia nos permitiu compreender as percepções que as adolescentes possuem sobre as formas de violência de gênero apresentadas nos casos no grupo Face, grupo que foi bem aceito por elas, que participaram ativamente, e que contribuiu de forma significativa para desinibi-las a expor suas opiniões. Acreditamos que a escolha dos casos foi conveniente, pois notamos a expressão de opiniões que estavam imbuídas de sentimentos e vivências sociais.

Percebemos que as mídias e as redes sociais abriram um leque de oportunidades e maneiras diferentes para as adolescentes evidenciarem os processos de subjetivação envolvidos na construção de sentidos sobre a violência de gênero em nossa sociedade. Então, lançar mão de recursos que fazem parte do cotidiano de estudantes permitiu um conforto e uma liberdade inimaginável, conferindo mais segurança para as mesmas, possibilitando maior e melhor interação entre as participantes do grupo Facebook Messenger. Nesta pesquisa-intervenção, as mídias fomentaram uma oportunidade única para a produção de conhecimentos que afetem estas adolescentes em suas relações cotidianas. Assim, percebemos o potencial das mídias sociais como espaços-tempos formativos para as adolescentes, podendo ser acionadas nos processos educativos na escola, visando o protagonismo dos estudantes frente a temáticas relacionadas à sexualidade.

Desse modo, é de suma importância colaborar para o autoconhecimento de adolescentes/mulheres, pessoas que lutaram e lutam diariamente por uma sociedade justa com mais equidade e menos patriarcado e culturas opressoras de silêncio cheias de misoginia. Por isso, esse trabalho vem a contribuir de maneira positiva na construção e percepção social das adolescentes, da importância do empoderamento feminino e do auto reconhecimento enquanto pessoa, que deve ser respeitada independente do gênero ou orientação sexual. 


\section{REFERÊNCIAS}

ARÁN, M; PEIXOTO JÚNIOR, C. A. Subversões do desejo: sobre gênero e subjetividade em Judith Butler. Cadernos Pagu, Campinas, v. 28, p. 129-147, 2007. Disponível em: http://www.scielo.br/pdf/cpa/n28/07.pdf. Acesso em: 30. mai. 2019.

BARROS, S. da C.; RIBEIRO, P. R. C. O sexting e o dispositivo da sexualidade. Ensino em Re-Vista, Uberlândia, v. 23, n. 2, p. 411-436. Disponível em: http://www.seer.ufu.br/index.php/emrevista/article/view/36493/19248. Acesso em: 30. mai. 2019.

BRASIL. Lei 8.069, de 13 de Julho de 1990. Estatuto da Criança e do Adolescente. Brasília: Ministério da Justiça, 1990. Disponível em: http://www.planalto.gov.br/ccivil_03/leis/18069.htm. Acesso em: 08. set. 2019.

BRETAS, J. R. da S. et al. Os rituais de passagem segundo adolescentes. Acta Paul Enferm, São Paulo, v.21, n. 3, p. 404-411, 2008. Disponível em: http://www.scielo.br/pdf/ape/v21n3/04. Acesso em: 08. set. 2019.

BUTLER, J. Violência de Estado, guerra, resistência: por una nueva politica de la izquierda. Madrid: Katz Editores, 2011. Disponível em: http://www.lauragonzalez.com/TC/BUTLER_violencia_de_estado.pdf. Acesso em: 30 . mai. 2019.

CORRÊA, F. S.; KODATO, S. As redes sociais e a discussão sobre dependência afetiva nas relações virtuais. Perspectivas em Psicologia, Uberlândia, v. 18, n. 2, p. 88-104, 2014 . Disponível em http://www.seer.ufu.br/index.php/perspectivasempsicologia/article/view/29646. Acesso em 05. set. 2019.

DELEUZE, G. Crítica e clínica. São Paulo: Editora 34, 2006.

EISENSTEIN, E. Adolescência: definições, conceitos e critérios. Adolescência \& Saúde, Rio de Janeiro, v. 2, n. 2, p. 6-7, 2005. Disponível em: http://www.adolescenciaesaude.com/detalhe_artigo.asp?id=167. Acesso em: 08. set. 2019.

FERNANDES, W. L.; SANTOS, G. L. Concepção de uma rede virtual de aprendizagem colaborativa para escolas agrotécnicas federais. TE em Revista, Distrito Federal, v. 1, n. 1, 2007.

FLICK, U. Introdução a pesquisa qualitativa. 3. ed. Porto Alegre: Artmed, 2009. p. 187.

FOUCAULT, M. Resumo dos cursos do Collège de France (1970-1982). Rio de Janeiro: Zahar, 1997. Disponível em: https://monoskop.org/images/0/06/Foucault_Michel_Resumo_dos_cursos_do_College_de_France 1970-1982.pdf. Acesso em 30. mai. 2019.

ILLOUZ, E. O Amor nos tempos do capitalismo. Tradução de Vera Ribeiro. Rio de Janeiro: Jorge Zahar, 2011.

KOZINETS, R. On netnography: initial reflections on consumer research investigations of cyberculture. Advances in Consumer Research, Duluth, v. 25, p. 366-371, $1998 . \quad$ Disponível em: http://www.acrwebsite.org/volumes/8180/volumes/v25/NA-25. Acesso em: 30. mai. 2019.

LINS, B. A. "Ih, vazou!": pensando gênero, sexualidade, violência e internet nos debates sobre "pornografia de vingança". Cadernos de Campo, São Paulo, n. 25, p. 246-266, 2016. Disponível em: http://www. revistas.usp.br/ cadernosdecampo/article/view/114851/134104. Acesso em: 08. set. 2019.

LOURO, G. L. Gênero, sexualidade e educação: uma perspectiva pós-estruturalista. 2. ed. Petrópolis-RJ: Vozes, 1998.

O corpo educado: pedagogias da sexualidade. Belo Horizonte: Autêntica, 2000a. Disponível em: https://core.ac.uk/download/pdf/30353576.pdf. Acesso em: 08. set. 2019.

Corpo, escola e identidade. Educação \& Realidade, Porto Alegre, v. 25, n. 2, 2000b. Disponível em: https://seer.ufrgs.br/educacaoerealidade/article/download/46833/29119. Acesso em: 30. mai. 2019.

Gênero, sexualidade e educação: das afinidades políticas às tensões teórico-metodológicas. Educação em Revista, Belo Horizonte, n. 46. p. 201-218, 2007. Disponível em: http://www.scielo.br/pdf/edur/n46/a08n46. Acesso em: 30. mai. 2019.

MATTAR, J. Design educacional: educação a distância na prática. São Paulo: Artesanato Educacional, 2014.

MORAN, J. M. Educação híbrida: Um conceito-chave para a educação hoje. In: BACICH, L.; TANZI NETO, A.; TREVISANI, F. de M. Ensino híbrido: personalização e tecnologia na educação. Porto Alegre: Penso, 2015.

NARVAZ, M; KOLLER, S. H. Famílias e patriarcado: da prescrição normativa à subversão criativa. Psicologia e sociedade, Belo Horizonte, v. 18, n. 1, p. 49-55., 2006. Disponível em: http://www.scielo.br/pdf/psoc/ v18n1/a07v18n1.pdf. Acesso em: 08. set. 2019. 
NOGUEIRA, E. J.; GOMES, L. F.; SOARES, M. L. de A. Netnografia: considerações iniciais para pesquisas em educação. Quaestio: revista de estudos em educação, Sorocaba, v. 13, n. 2, p. 185-202, 2012. Disponível em http://periodicos.uniso.br/ojs/index.php/quaestio/article/view/696/720. Acesso em: 30. mai. 2019.

PARANÁ. Estudos de caso violência de gênero. 2015. Disponível em: http://www.educadores.diaadia.pr.gov. br/arquivos/File/formacao_acao/2semestre_2015/estudos_de_caso_fa_dedi_genero.pdf. Acesso em: 30. mai. 2019.

PASSOS, E.; BARROS, R. B. de. A cartografia como método de pesquisa-intervenção. In: PASSOS, Eduardo; KASTRUP, V.; ESCÓSSIA, L. da. Pistas do método da cartografia: pesquisa-intervenção e produção de subjetividade. Porto Alegre: Sulina, 2009.

PATRÍCIO, M. R.; GONÇALVES, V. Facebook: rede social educativa? In: ENCONTRO INTERNACIONAL TIC E EDUCAÇÃO, 1. 2010, Lisboa. Anais... Lisboa: Universidade de Lisboa, 2010, p. 593-598. Disponível em: https://bibliotecadigital.ipb.pt/bitstream/10198/3584/1/118.pdf. Acesso em: 30. mai. 2019.

RECUERO, R. Redes sociais na internet. 2. ed. Porto Alegre: Sulina, 2011 (Coleção Ciberculltura).

SANTANA, A. M. As relações de gênero, sexualidade e violência nos processos de separação/divórcio. Revista Aurora, Marília, v. 3, n. 2, p. 89-99, 2010. Disponível em: http://200.145.171.5/revistas/index. php/aurora/article/view/ 1235. Acesso em: 06. set. 2019.

SIBILIA, P. O bisturi de software: como fazer um 'corpo belo' virtualizando a carne impura? In: ARAÚJO, D. C. (Org.). Imagem (ir)realidade: comunicação e cibermídia. Porto Alegre: Sulina, 2006. p. 284.

VICENTE, L. M. D.; A sujeição performativamente engendrada: atravessamentos entre os estudos de Judith Butler e os modos de subjetivação em Michel Foucault. Revista Periódicus, Salvador, v. 1, n. 3, p. 85-103, 2015. Disponível em: https://portalseer.ufba.br/index.php/revistaperiodicus/article/view/14257/9859. Acesso em: 08. set. 2019. 


\section{RESUMO}

Este artigo tem como objetivo mapear sentidos sobre a violência de gênero entre adolescentes de uma escola pública na Bahia, com a mediação de redes sociais. Todo o processo foi desenvolvido a partir de um grupo Facebook Messenger, em que as estudantes foram convidadas a expressarem suas opiniões sobre situações cotidianas que enfrentam em suas relações e as violências que as permeiam. O grupo envolveu nove meninas que debateram sobre três casos: "Sexting", "Violência de gênero em sala de aula" e "Violando o direito de livre expressão da orientação sexual". Esta mídia social apresentou-se como um espaço-tempo formativo a ser acionado na escola, visando o protagonismo dos estudantes frente a temáticas relacionadas a gênero e sexualidade.

Palavras-chave: Sexualidade. Violência de Gênero. Facebook Messenger.

\section{CARTOGRAPHING GENDER VIOLENCE CASES IN A GROUP ON FACEBOOK}

\section{ABSTRACT}

This article aims to map meanings about gender violence among adolescents at a public school in Bahia, with the mediation of social networks. The whole process was developed from a Facebook Messenger group, in which the students were invited to express their opinions about everyday situations they face in their relationships and the violence that permeates them. The group involved nine girls wich discussed three cases: "Sexting", "Gender Violence in the Classroom" and "Violating the Right to Free Expression of Sexual Orientation." This social media presented itself as a formative space-time to be activated in the school, aiming at the protagonism of the students facing the themes related to gender and sexuality.

Keywords: Sexuality.Gender Violence. Facebook Messenger.

\section{CARTOGRAFANDO CASOS DE VIOLENCIA DE GÉNERO EN UN GRUPO EN EL FACEBOOK}

\section{RESUMEN}

Este artículo tiene como objetivo mapear sentidos sobre la violencia de género entre adolescentes de una escuela pública en Bahía, con la mediación de redes sociales. Todo el proceso fue desarrollado a partir de un grupo Facebook Messenger, en el que las estudiantes fueron invitadas a expresar sus opiniones sobre situaciones cotidianas que enfrentan en sus relaciones y las violencias que las permean. El grupo contó con nueve niñas que debatieron sobre tres casos: "Sexting", "Violencia de género en el aula" y "Violando el derecho de libre expresión de la orientación sexual". Este medio social se presentó como un espacio-tiempo formativo a ser accionado en la escuela, visando el protagonismo de los estudiantes frente a temáticas relacionadas a género y sexualidad.

Palabras clave: Sexualidad.Violencia de Género. Facebook Messenger. 